\title{
DONGGALA:
}

\section{FROM IMPERALISM TO THE REGENCY ESTABLISHMENT}

Oleh:

\author{
Lukman Nadjamuddin $^{1}$ and Idrus ${ }^{2}$
}

\section{Abstract}

The Effort exerted by the Dutch to conquer Banawa Kingdom, particularly Donggala City, began with the assumption derived from economic and political calculation that the confiscation would make it possible for the Dutch to pacify its trade channel in Makasar narrows and extend economic exploitation, given that Donggala had a strategic port, related to the chain of Archipelago's trade. The method of confiscation-friendship relation was not realized because resistances, in the form of physical attack-began to come forward. In Donggala, Molanda played a role as the main actor in the rebellion. In Sigi, Toma I Dompo consistently attacked, both after and before arrested in Sukabumi. In Sojol, Toma Tarima along with his son assailed the Dutch and in Kulawi, Toma Itorengke set about the Dutch as well.

During the Japanese imperialism, the education system of the Dutch was eliminated, and replaced with Japanese education which required to speak Japanese and Indonesia languages, to sing Kimigayo, to give respect to Hinomaru, to do Seikrei, Kinrohosyi and Taiso. The social and political organization was limited, while those which supported the mass mobilization were established, such as Seinendan. This led the nationalists to do the underground movement. In the agriculture, native people were obligated to plant cotton, rice, corn and cassava as to overcome the lack of food and clothing.

After the independence was announced, Donggala faced by two struggle NICA attack and to establish the Donggala Regency. The effort to maintain the freedom was conducted in two ways, physical struggle and establish of social and political organization, while the establishment of Donggala Regency gained two important momentum; the establishment of Administrative region of Donggala on the basis of Sulawesi Governor's verdict no. 633 on October 25 th 1951 and the establishment of Donggala Regency on the basis of Government regulation no.33 on August $12^{\text {th }} .1952$.

Keyword: Donggala, Imperialism, Regency.

1 Dosen pada Program Studi Pendidikan Sejarah serta pembantu dekan III FKIP Universitas Tadulako, Palu.

2 Widyaiswara pada LPMP Sulawesi Tengah serta dosen luar biasa pada Program Studi Pendidikan Sejarah, FKIP Universitas Tadulako, Palu. 


\section{A. Pendahuluan}

Donggala yang menjadi fokus kajian dalam penelitian ini adalah sebuah kota tua yang kondisi masyarakatnya heterogen dan sejak lama telah berinteraksi dengan dunia luar. Meskipun demikian, kajian sejarah lokal oleh sejarawan yang berkembang pesat belakangan ini belum banyak menyentuh Donggala. Muklis Paeni ${ }^{3}$ merumuskan bahwa sejarah lokal berhubungan dengan kisah dari hal ikhwal masa lampau masyarakat yang berada pada suatu ruang lingkup geografis yang terbatas. Keterbatasan ruang lingkup geografis tidak berarti meniadakan pengaruh luar yang merubah keadaan lokal.

Sebutan Donggala bersumber dari Don 'Nggolo, nama kapten kapal Spanyol yang merapat di muara Teluk Palu pada tahun 1200 untuk mengisi air tawar. Sebutan Don 'Nggolo kemudian berubah menjadi Donggala sesuai dialek setempat dan sejak itu kata Donggala mulai diperkenalkan. ${ }^{4}$ Dalam literatur Perancis kata Donggala disebut dengan kata Dunggally. Pemuatan kata Dunggally tersebut dapat dilihat dalam peta tua Pulau Sulawesi yang dibuat pada tahun 1805 oleh D. Woodard, sementara peta Pulau Sulawesi yang dibuat oleh Lodocus Hondius pada tahun 1611, Donggala disebut dengan istilah Durate. $^{5}$

Metode yang digunakan dalam penelitian ini mengikuti prosedur kerja dalam penelitian sejarah yang dikemukakan oleh Isaiah Berlin ${ }^{6}$, yakni berusaha menemukan, melukiskan, dan menerangkan aspek sosial serta akibat yang ditimbulkan oleh apa yang dilakukan dan diderita manusia. Menurut Louis Gottschalk ${ }^{7}$ prosedur metode sejarah meliputi pengumpulan informasi yang diperlukan dari berbagai sumber, pengujian otentisitas sumber-sumber yang didapatkan (kritik eksternal) dan penentuan kredibilitas sumber-sumber yang ditemukan (kritik internal).

${ }^{3}$ Muklis Paeni, 1985. Sejarah Kabupaten Daerah Tk. II Sidenreng-Rappang, Ujung Pandang: Universitas Hasanuddin, hal ii.

${ }_{4}^{4}$ Andi Mas Ulun Parenrengi Lamarauna, 1998. Pelabuhan Donggala dalam Tinjauan Sejarah. Manuskrip, hal 1.

${ }^{5}$ E.J. BRILL, 1918. "La Cartographic Neerlandaise de La Celebes, D'Apres Des Modeles Etrangers 1590-1670," dalam: E. C. Abendanon, Expedition De La Celebes Centra Ie, Voyages Geologiques Et Geographiques A Travers La Celebes Centrale 1909-1910. Leyde: Librairie et Imprimerie Ci-Devant, hal 1457.

${ }^{6}$ T.B. Bottomore, 1971. Sociology: A Guide to Problem and Literature. London: George Alien \& Unwin Ltd, hal 308.

${ }^{7}$ Louis Gottschalk, 1986. Terj. Nugroho Notosusanto, Mengerti Sejarah. Jakarta: Penerbit Universitas Indonesia, hal 32. 
Jenis-jenis sumber yang digunakan dalam penelitian ini adalah sumber primer dan sekunder. Sumber primer berupa Besluit van Gouverneur Generaal, Besluit van Resident Manado, Memorie van Overgave Afdeling Donggala, Koloniaal Verslag, Indische Verslag, Politik Verslag, Regeerings Almanak van Nederlandsch Indie, dan Staatsblad van Nederlandsch Indie. Sumber sekunder adalah buku, jurnal, dan hasil wawancara saksi sejarah atau yang memiliki pengetahuan tentang sejarah Donggala, terutama pada masa pendudukan Jepang dan setelah kemerdekaan.

Penelitian ini berusaha menjawab pertanyaan: (1) bagaimana bentuk hegemoni pemerintahan Belanda dan resistensi yang muncul; (2) bagaimana proses pendudukan Jepang dan dampaknya dalam kehidupan sosial; dan (3) bagaimana dinamika setelah kemerdekaan dan proses penetapan Donggala sebagai Kabupaten?

\section{B. Hegemoni Pemerintahan Belanda dan Munculnya Resistensi}

Berdasarkan surat keputusan Gubernur Jenderal tanggal 18 Agustus $1924,{ }^{8}$ Sulawesi memiliki dua karesidenan, yakni Sulawesi serta bawahannya dan Manado. Untuk karesidenan Manado terbagi dalam lima afdeling, yakni: Afdeling Manado, Afdeling Gorontalo, Poso, Donggala, dan Afdeling Kepulauan Sangihe \& Talaud. Afdeling Donggala terbagi dalam empat onderafdeling yakni: Onderafdeling Donggala, Palu, Parigi, dan Onderafdeling Tolitoli. Perkembangan berikutnya, Afdeling Donggala berubah menjadi Afdeling Sulawesi Tengah yang diikuti dengan pembagian sejumlah onderafdeling sebagai berikut: ${ }^{9}$ (1) Teluk Palu, yang mencakup daerah Palu, Sigi-Biromaru, Dolo, Rindau, Dolo Kaleke, Banawa atau Donggala, Tavaeli dan daerah sekitarnya di bawah civiel gezaghebber yang berkedudukan di Donggala; (2) Tolitoli di bawah seorang civiel gezaghebber yang berkedudukan di Kampung Baru; dan (3) Teluk Tomini yang mencakup Moutong, Sigenti, Kasimbar, Toribulu, Ampibabo, Parigi, Sausu, Poso, Tojo, Kepulauan Togean dan Una-Una serta Mapane di bawah Kontrolir.

8 Staatsblad Nederlansch-Indie No. 366, tahun 1927 dan Army van den Boch, op.cit., hal 138.

9 ANRI, "Besluit van Gouverneur Generaal 9 December 1904", bundel Algemeen Secretarie. 
Sektor ekonomi yang mempengaruhi kehidupan masyarakat dan menentukan perkembangan Donggala menjadi sasaran eksploitasi pemerintah Belanda sejak dekade terakhir abad XIX dan semakin intensif ketika memasuki abad XX. Kebijakan ekonomi kolonial bukan hanya ditopang oleh kepentingan pemerintah kolonial, tetapi juga ditentukan oleh kepentingan kapitalis swasta. Bersamaan dengan intensifikasi dalam perdagangan kopra di Makassar dan Manado, pemerintah Belanda juga mencoba untuk mencari pasokan kopra dalam jumlah memadai di Donggala. ${ }^{10}$

Untuk kepentingan pengangkutan kopra dari pelabuhan Donggala ke Jawa dan Eropa, pemerintah kolonial membuat kontrak dengan perusahaan perkapalan Koninklijke Paketvaart Maatschappij (KPM) yang menerima hak monopoli untuk mengelola armada pengangkutan di seluruh wilayah Hindia Belanda. KPM memiliki kapal-kapal yang digerakkan oleh tenaga uap dengan tonase cukup besar. Dengan demikian KPM berhasil menghubungkan antara Jawa dan seluruh wilayah di luar Jawa, kemudian menghubungkan antara daerah-daerah tertentu di luar Jawa dan Jawa dengan pusat-pusat konsumen produk tropis di Eropa dan Asia. ${ }^{11}$ Dari 14 jalur pelayarannya, KPM mencantumkan pelabuhan Donggala sebagai salah satu jalur yang menghubungkan pelabuhan Surabaya dengan pelabuhan Makassar dan Manado.

Produk lain yang menjadi sasaran eksploitasi adalah hasil hutan terutama kayu besi, kayu hitam, rotan, dan damar, karena harganya yang mahal di pasar internasional. Kayu dan produk hutan lainnya diangkut dengan kapal-kapal KPM dari pelabuhan Donggala, kemudian dibawa ke pasar lelang kayu di Surabaya dengan harga yang tinggi, sehingga pemerintah Belanda memperoleh keuntungan yang besar. $^{12}$ Dalam eksploitasi kayu, pemerintah kolonial mengalami kesulitan, karena prasyarat utama yang diperlukan adalah ketersediaan modal usaha dan pengetahuan memadai tentang hasil hutan

10 H.J. Vingerhoets, 1933. "Coprahcontracten in de Minahassa", dalam Koloniaal Tijdschrift, jilid ke-22, hal 301 - 310.

${ }^{11}$ J.A. Campo, 1994. "Steam navigation and state formation", dalam Robert Cribb (ed.) The Late Kolonial State in Indonesia: Political and Economic Foundations of the Netherlands Indies 18801942. Leiden: KITLV Press, hal 18. Posisi yang diraih oleh KPM dalam pelayaran uap di Hindia Belanda ini sering digambarkan sebagai monopoli baru oleh sebuah perusahaan perkapalan atas perdagangan dan pengangkutan inter-regional dan internasional.

12 J.S. van Braam, 1914. "De Buitenbezittingen en het boschwezen", Tijdschrift voor Binnenlands Bestuur, jilid 47, hal 275-290. Surabaya merupakan pusat lelang kayu untuk kawasan Indonesia bagian Timur. 
tersebut. Kedua prasyarat itu tidak dimiliki oleh pemerintah kolonial, sehingga solusi yang ditempuh adalah melibatkan pihak swasta untuk memborong konsesi ekploitasi hutan. Pada tahun 1891 dilakukan pelelangan untuk eksploitasi kayu selama 40 tahun dan penawar tertinggi diajukan oleh firma Lamerts van Bueren. ${ }^{13}$ Sebelum melakukan eksploitasi, perusahaan ini membagi tiga hutan Dampelas yakni Levono, Mafida, dan Kaliburu. Firma ini membuka kantor cabang di Batusuya untuk mengawasi eksploitasi hutan di Dampelas. Kebutuhan tenaga kerja dipenuhi dengan cara mendatangkan para kuli tebang dari daerah lain dengan gaji harian.

Firma Lamerts van Beuren mengeksploitasi secara besar-besaran jenisjenis kayu dan hasil hutan yang memiliki nilai jual tinggi di pasar internasional. Dalam masa kontrak selama 40 tahun, Firma Lamerts van Beuren tidak melakukan peremajaan sehingga hutan Dampelas menjadi gundul dan kritis. Ketika pemerintah kolonial membutuhkan kayu untuk pembangunan infrastruktur, harus membeli dengan harga tinggi dari firma. Hal ini dianggap sebagai kerugian bagi pemerintah kolonial, sehingga Residen Manado mengusulkan kepada pemerintah pusat di Batavia agar tidak memperpanjang konsesi Firma Lamerts van Beuren tersebut. Pada tahun 1931, ketika masa konsesi firma ini berakhir dan meminta perpanjangan konsesi, pemerintah Batavia menolak kemudian mengambil alih konsesi hutan Dampelas dari firma tersebut. ${ }^{14}$

Sasaran monopoli lainnya oleh pemerintah kolonial adalah garam. Di Donggala, terutama di daerah Banawa, pembuatan garam dilakukan secara tradisional yakni menguapkan air laut. Konsumen garam terbesar terdapat di Banawa Selatan dan Sirenja karena kondisi geologi kedua daerah ini yang tidak memungkinkan pembuatan garam sehingga harus membeli dari tempat lain. Ketika terjadi pertumbuhan ekonomi dan perluasan pemukiman di Donggala, kebutuhan garam sebagai konsumsi sehari-hari semakin meningkat. Pemerintah kolonial melihat peluang tersebut sebagai sesuatu yang menguntungkan sehingga mengambil alih perdagangan garam. ${ }^{15}$

Untuk menopang akses ekonomi dan politik, pemerintah membangun jalan, antara lain: (1) Donggala-Watusampu 20 km; (2) Donggala-Tulongano 21

${ }^{13}$ Koloniaal Verslag over het jaar 1891, hoofdstuk C, hal 16 - 17.

14 ANRI, "Besluit van Resident Manado 17 Agustus 1931 no. 28/1/3", bundel Algemeen Secretarie.

15 ANRI, “Agenda Nomor 11952/07”, bundel Algemeen Secretarie. 
km sepanjang pantai dari Limboro; (3) Tondo (batas Palu-Tavaeli)-Siojong 144 km; dan (4) Donggala ke arah Selatan sampai Siruyu $35 \mathrm{~km}$ dengan dua cabang Tanjung Karang $32 \mathrm{~km}$ dan Kola-Kola $2 \mathrm{~km}$ sebagai perpanjangan jalan di Polege (jalan ini menuju ke Siruyu arah Selatan) ke arah Watu dan Surumana. Setelah pembuatan jalan dirampungkan, program berikutnya membuat jembatan, terutama yang menghubungkan antara kota Donggala dan pelabuhan yang menghabiskan biaya sebesar f 3.713.59.

Menyadari peran strategis pelabuhan Donggala, pemerintah Belanda membangun sejumlah fasiltas, seperti gudang dan dermaga. Peran strategis tersebut sudah lama berlangsung, karena pada masa pemerintahan Raja Banawa II, pelabuhan Donggala ramai dikunjungi perahu-perahu besar dan kapal dagang milik orang asing, ${ }^{16}$ bahkan pada era pemerintahan Raja Banawa III, berperan sebagai "penghubung" dengan kerajaan-kerajaan luar seperti kesultanan Ternate, kerajaan Gowa, Bone, dan Mandar untuk kepentingan perdagangan kopra, rotan, kayu, damar, dan sapi. Pada masa pemerintahan raja Banawa V, pelabuhan Donggala menjadi tempat bertemu antara pedangang Gujarat, Cina, dan Arab, sehingga perhiasan emas, permata, serta kain dan benang sutra berdatangan di Pelabuhan Donggala yang dibarter dengan kopra, rotan, dan damar. ${ }^{17}$. Stibbe mencatat bahwa tahun 1914. Pelabuhan Donggala menjadi pelabuhan terbanyak kedua dikunjungi kapal-kapal asing jenis kapal uap dan kapal layar setelah pelabuhan Manado dalam wilayah Residen Manado. ${ }^{18}$

Obsesi Pemerintah Belanda untuk menjadikan Donggala sebagai basis perekenomian di Sulawesi Tengah disertai hegemoni politik berdampak pada munculnya resistesi dalam bentuk perang fisik di berbagai daerah. Di kota Donggala, Malonda mengambil peran sebagai aktor utama pembangkangan terhadap Belanda; Di Sigi, Toma I Dompo, secara konsisten melawan, baik sebelum ditawan maupun setelah ditawan; Di Sojol, Toma Tarima bersama anaknya melawan Belanda; dan di Kulawi Toma Itorengke melakukan hal serupa. Dari sekian banyak bentuk perlawanan terhadap Belanda, tampaknya sumber tertulis lebih banyak menjelaskan tentang Toma I Dompo. Perlawanan Toma I Dompo, terutama disebabkan oleh kerja wajib dalam penyediaan lahan

16 Andi Mas Ulun Parenrengi Lamarauna, 1998. Pelabuhan Donggala dalam Tinjauan Sejarah. Manuskrip, hal 2.

17 Ibid., hal 3.

18 Stibbe, D.G. 1935. Encyclopaedic Van Nederlandsch Indie, S-Gravenhage: Martnus Nijhoff, hal. 395 
untuk pembangunan jalan, material bangunan yang ada di lokasi pembangunan tanpa ganti rugi, dan tenaga kerja wajib tanpa dibayar. Ketiga tuntutan itu dianggap oleh Toma I Dompo sebagai pelanggaran atas kewenangannya dan akan banyak merampas tanah di wilayah Biromaru.

Pada awal Desember 1904, Engelenberg memerintahkan memulai pembangunan jalan di Tambarana. Ditempat ini, Toma I Dompo diwajibkan untuk menyiapkan tenaga kerja dan material bangunan. Ketika hari mulai siang para pekerja istirahat, Engelenberg memerintahkan agar terus bekerja, tetapi mereka menolak. Engelenberg memerintahkan aparat pribumi untuk bertindak tegas, akibatnya rakyat menjadi marah dan menyerang aparat pemerintah. Pertempuran tidak dapat dihindarikan. Beberapa orang aparat pemerintah terbunuh dan terluka, tetapi Engelenberg dan Intje Dahlan berhasil menyelamatkan diri.

Engelenberg segera meminta kepada komandan pasukan Belanda di Donggala, Kapten Mazee, untuk mengirim pasukan ke Tambarana. Orang-orang Biromaru yang dipimpin Toma I Dompo masih menguasai Tambarana sepanjang hari dan bertekad untuk melakukan perlawanan. Pasukan Belanda yang terdiri atas 20-an serdadu bersenjata api tiba di Tambarana dan langsung menyerbu pengikut Toma I Dompo. Pertempuran terjadi kembali, pasukan Belanda berhasil membubarkan konsentrasi orang Biromaru. Beberapa korban jatuh dan lainnya lari menyerahkan diri kepada Engelenberg dan bersedia mengerjakan jalan sesuai dengan instruksinya. ${ }^{19} \mathrm{Di}$ antara mereka adalah Papa I Jaelani dan Papa I Tarumpae yang bersedia membayar denda sebagai kompensasi atas perbuatan mereka. Engelenberg tidak mentaati janji yang diberikan bahwa mereka yang menyerah dan telah membayar pajak akan dibebaskan dan dikembalikan pada posisinya. Kedua pembantu Toma I Dompo tersebut tetap ditahan dan diadili. Pada bulan September 1905 atas keputusan Landraad Donggala, Papa I Jaelani dan Papa I Tarumpae tidak diperkenankan tinggal di wilayah Sulawesi Tengah. Pada bulan Oktober 1905, beberapa tokoh pengikut Toma I Dompo antara lain; Hanusu dan penguasa Pakawa ditangkap. ${ }^{20}$

${ }_{19}$ Koloniaal Verslag over het jaar 1906, hoofdstuk C. Di antara mereka yang berhasil lolos adalah Papa I Lila dan Uma I Baturu yang merupakan orang-orang kepercayaan Karanjalemba atau Toma I Dompo untuk memimpin orang-orang Biromaru.

${ }^{20}$ Koloniaal Verslag over het jaar 1910. Daerah Pekava belum aman meskipun penguasanya telah ditangkap, Pimpinan baru yaitu I Gompo tetap tidak mau menjalankan perintah 
Setelah keamanan di Tambarana dipulihkan, pasukan Belanda di bawah pimpinan Kapten Mazee bergerak menuju Biromaru untuk menangkap Toma I Dompo. Tanpa banyak perlawanan, Biromaru berhasil diduduki dan Toma I Dompo bersama keluarganya ditangkap dan ditahan di Watunonju sebelum dibawa ke Donggala. ${ }^{21}$ Setelah interogasi terhadap Toma I Dompo dilakukan, Engelenberg menerima perintah dari Residen Manado untuk membawa Toma I Dompo ke Manado menghadiri persidangan di Pengadilan Negeri (landraad) di Manado. Ketika sampai di Manado, Toma I Dompo langsung dimasukkan dalam penjara untuk mempermudah pengumpulan bukti dan data mengenai keterlibatannya dalam gerakan melawan pemerintah. Dalam persidangan pada pertengahan Mei 1906, dituduh dengan dakwaan primer melakukan makar terhadap pemerintahan yang sah dan dakwaan sekunder, dianggap telah membangkang instruksi pemerintah untuk membuat jalan dari Biromaru ke Donggala, melanggar korte verklring yang telah ditandatanganinya, dan menghambat program pemerintah untuk meningkatkan kesejahteraan masyarakat.

Landraad maupun Residen Manado tidak bisa menjatuhkan vonis sehingga menyerahkan besarnya hukuman bagi Toma I Dompo kepada pemerintah pusat di Batavia. Atas pertimbangan dari Direktur Kehakiman, Gubernur Jenderal J. B. van Heutsz diputuskan hukuman sepuluh tahun pembuangan di Sukabumi. Setelah mempertimbangkan usul dari Direktur Pemerintahan (Binnenlandsch Bestuur), ${ }^{22}$ pada minggu pertama bulan Juni 1906, Toma I Dompo diberangkatkan ke Sukabumi dengan kapal uap milik KPM.

Sampai tahun 1913, stabilitas keamanan di Sigi tidak bisa dikendalikan, terutama di pegunungan Larangganau dan Pekava, serta kerja wajib yang sukar diterapkan. Pemerintah kolonial mengambil kebijakan untuk mengembalikan Toma I Dompo dari Sukabumi. Pengaruh Toma I Dompo yang masih besar di Biromaru menjadikan pemerintah Belanda berharap dapat membuat kesepakatan dengan Toma I Dompo agar bersedia menjadi mediator untuk melaksanakan instruksi dalam membuka jalan di pedalaman. Toma I Dompo

pemerintah dan akhirnya pasukan militer dikirim ke Pekava tanggal 1 September 1909 untuk memaksanya menyerah.

${ }^{21}$ Koloniaal Verslag over het jaar 1906, hoofdstuk C. Menurut laporan Kapten Mazee, dalam perjalanan kembali dari Biromaru perlawanan pengikut Toma I Dompo jalan BiromaruPalu sangat mengganggu. Akibatnya untuk sementara Toma I Dompo ditempatkan di Watunonju dan tidak dibawa ke Donggala.

${ }^{22}$ ANRI, Besluit van Gouverneur Generaal 3 Juni 1906 no. 14, bundel Algemeen Secretarie. 
juga akan dijamin dikembalikan pada posisi lamanya sebagai penguasa Biromaru dan diminta untuk menenangkan kembali daerah Larangganau dan Pekava. Atas keputusan dari pemerintah di Batavia, maka pada bulan Juni 1915, Toma I Dompo dibebaskan dari tahanannya di Sukabumi dan kembali ke Biromaru. ${ }^{23}$

Setibanya di Biromaru, sesuai dengan instruksi pemerintah Belanda, Toma I Dompo menemui para pemimpin To Larangganau di pegunungan Biromaru. Pertemuan yang berlangsung bulan November 1916 dengan para tokoh To Larangganau, dimanfaatkan untuk menyampaikan maksudnya mengembalikan kekuasaan kerajaan Biromaru seperti sebelum tahun 1907. Pembicaraan kemudian tidak lagi menyangkut masalah pembukaan jalan, tetapi menyusun kekuatan untuk melawan tekanan pemerintah kolonial. Para bangsawan Biromaru dan penguasa yang berpengaruh di Larangganau mendukung maksud tersebut. ${ }^{24}$

Pada akhir Maret 1917, Toma I Dompo mengundang tokoh Biromaru dan Larangganau dalam upacara adat Mentaka di desa Manusi untuk meminta restu para roh leluhur agar memberikan kemenangan dalam peperangan. Upacara adat ini ditandai dengan pemotongan seekor kerbau dan boneka kayu yang melambangkan seorang budak. Darah kerbau kemudian dipercikkan kepada semua orang yang hadir karena dianggap sebagai zimat kekebalan menghadapi senjata musuh. Setelah berakhirnya upacara itu, seruan perlawanan disebarkan ke segala penjuru hingga ke Palu. ${ }^{25}$ Rencana tersebut diketahui oleh Civiel Gezaghebber Palu, sehingga memerintahkan pasukan militer untuk berangkat ke Biromaru yang dengan cepat berhasil mengepung rumah Toma I Dompo dan menangkapnya tanpa perlawanan. Toma I Dompo kemudian dibawa ke Donggala untuk diadili dengan tuduhan penyalahgunaan kekuasaan, dan kembali dijatuhi hukuman seumur di Sukabumi. ${ }^{26}$

${ }^{23}$ Koloniaal Verslag over het jaar 1915, hoofdstuk C, hal 33-34. Pengaruh Toma I Dompo ini masih cukup besar yang dari penyambutan para bangsawan Biromaru di pelabuhan Donggala ketika kembali dari pengasingan.

24 ANRI, "Missive van Gouvernement Secretaris tanggal 3 November 1916 no. 461", bundel Algemeen Secretarie. Residen Kroon dan Asisten Residen Grijzen telah menyampaikan keberatannya terhadap pengembalian Toma I Dompo ke Biromaru karena keduanya menduga bahwa akan timbul masalah baru dengan tokoh ini.

${ }^{25}$ Koloniaal Verslag over het jaar 1917, hoofdstuk C, hal 33-34.

26 ANRI, "Nota voor den adviseur voor de bestuurszaken der buitenbezittingen ajun adviseur voor Bestuurszaken der Buitenbezittingen AJ. Knaap", Besluit van Gouverneur Generaal 12 Mei 1917 no. 1, bundel Algemeen Secretarie. Toma I Dompo 
Orang-orang Larangganau di bawah pimpinan I Ngaja yang mendengar berita tentang penangkapan Toma I Dompo, melarikan diri ke pegunungan untuk menghindari penangkapan pasukan kolonial. Pengejaran terus dilakukan, sehingga pada bulan Oktober 1917, I Ngaja berhasil ditangkap dan dibawa ke Biromaru. Orang-orang Larangganau diperintahkan untuk kembali ke pemukimannya, tetapi sebagian besar tetap melakukan perlawanan hingga ke daerah Sausu. Meskipun semua perlawanan berhasil dipatahkan, tetapi aktivitas di Larangganau masih dianggap mengganggu keamanan dan ketertiban umum. Karena itu, pada bulan Oktober 1918 dengan alasan untuk merayakan panen besar, Kontrolir Palu melaksanakan pesta rakyat di kampung Janu, tempat pemukiman orang-orang Larangganau yang menyerah dan berharap para pelarian yang lain bersedia kembali. Keinginan ini tidak terwujud, sehingga Kontrolir Palu mengirim tiga orang tokoh Larangganau untuk mendatangi orang-orang yang masih bersembunyi di Sausu. Para pemberontak di bawah pimpinan Labarisi tidak bersedia menyerah, tetapi sebaliknya menyerang utusan Kontrolir Palu tersebut. ${ }^{27}$

Kontrolir Palu kemudian mengirimkan pasukan untuk mengejar para pemberontak Larangganau. Akibat serangan ini, kaum pemberontak terpecah menjadi dua: satu kelompok di bawah pimpinan Labarisi bertahan di Biromaru, sementara kelompok lain di bawah pimpinan Lalowe bergerak menuju Parigi. Pengejaran terhadap keduanya terus dilakukan, sehingga pada bulan Juli 1919, Lalowe terdesak dalam suatu operasi militer di Parigi dan tertangkap. Lalowe dibawa ke Palu untuk diadili. Melalui operesi militer pada bulan Desember 1919, Labarisi berhasil ditangkap di Biromaru kemudian ditahan di Palu. Sejak itu perlawanan masyarakat Larangganau berhenti, ${ }^{28}$ tetapi gangguan keamanan yang bersifat kriminal masih terus berlangsung sampai akhir pemerintahan Belanda.

\section{Pendudukan Jepang}

Pada bulan April 1942, pasukan Angkatan Laut Jepang (Kaigun) tiba di Donggala dengan kapal penjelajah bersama beberapa kapal pemburu torpedo, kemudian menemui raja-raja lokal di Donggala. Sebelum pendaratan dimulai, Pelabuhan Donggala dihujani bom sehingga bangunan sepanjang pantai hancur

dituduh menyalahgunakan kepercayaan yang diberikan kepada pemerintah Belanda dan menjadi tokoh pengganggu keamanan dan ketertiban di wifayah Sulawesi Tengah.

${ }^{27}$ Koloniaal Verslag over het jaar 1919, hoofdstuk C, hal. 71.

${ }^{28}$ Koloniaal Verslag over het jaar 1920, hoofdstuk C. 
rata dengan tanah. ${ }^{29}$ Setelah tentara Jepang mendarat, langsung mencari pejabatpejabat pemerintahan Belanda, tetapi Asisten Residen Donggala de La Vuente bersama keluarganya telah menyingkir ke Napu, bergabung dengan temantemannya, menuju Kolonodale.

Periode pendudukan Jepang, semua pendidikan pribumi dan pendidikan peninggalan Belanda dihapuskan dan digantikan dengan sistem pendidikan Jepang didominasi oleh kurikulum pelajaran Jepang seperti lagu-lagu dan bahasa Jepang, kemudian dilarang mengunakan bahasa Belanda. Lagu Kimigayo harus dihafal dan dinyanyikan oleh murid-murid sekolah setiap melakukan upacara bendera. Murid-murid sangat takut kepada guru, sehingga mereka menghafal lagu tersebut, karena jika ada yang tidak menghafal akan mendapat hukuman. ${ }^{30}$ Taiso (olah raga) juga menjadi bahan ajar yang penting. Tujuan Jepang melakukan pembinaan olah raga adalah merupakan strategi untuk persiapan perang, karena mengharapkan hanya orang Jepang di Indonesia itu tidak mungkin sehingga mereka juga membutuhkan tentara cadangan dari penduduk.

Masa pendudukan Jepang menyebabkan, hubungan dagang dengan daerah lain menjadi terputus, sehingga tidak ada kapal komersial yang berlabuh di pelabuhan Donggala. Kalaupun ada yang berlabuh, berada di bawah pengawasan tentara Sekutu dan tidak diperbolehkan melakukan bongkar muat logistik untuk kepentingan Jepang. Hal ini menyebabkan pakaian sangat sulit diperoleh, umumnya pakaian dibuat dari karung atau kain kasur yang telah dikeluarkan kapuknya. Akhirnya rakyat diwajibkan menanam kapas untuk diolah menjadi bahan pakaian. Rakyat juga kekurangan bahan makanan sehingga diwajibkan menanam singkong sebagai bahan makanan. Tanaman lain yang diharuskan ditanam adalah labuh, kentang, dan padi, juga diwajibkan menanam kama yang akan dijadikan bahan baku membuat karung. ${ }^{31}$

Tanaman kapas merupakan prioritas utama sehingga perawatannya dilakukan secara teratur. Jika diketahui ada yang menanam tanaman lain diselasela tanaman kapas, seperti tanaman jagung dan kacang maka akan mendapat hukuman, bahkan jika di antara tanaman kapas terdapat rumput yang lebat, Jepang tidak segan-segan untuk menampar pemilik kebun kapas tersebut. Hal

${ }^{29}$ Wawancara dengan Tomas di Donggala pada tanggal 20 Juni 2006.

${ }^{30}$ Wawancara dengan Lubis Ponulele di Biromaru Donggala pada tanggal 25 Juni 2006.

${ }^{31}$ Ibid., 
ini pernah dialami oleh Mama Yakan yang ketahuan menanam kacang dan jagung di kebun kapasnya.

Perlawanan rakyat Donggala terhadap pendudukan Jepang tidak seheroik di Tolitoli, Poso, dan Luwuk, karena resistensi dilakukan dalam bentuk gerakan di bawah tanah, yang dipengaruhi oleh tokoh-tokoh merah putih Gorontalo. Dalam buku Sejarah Sulawesi Tengah dinyatakan bahwa:

"Pergerakan di bawah tanah di Sulawesi Tengah pada mula hubungannya dengan pergerakan Merah Putih di Gorontalo sejak pada masa-masa menjelang kedatangan Jepang dan dilanjutkan pada masa pendudukan Jepang sampai ketika Jepang kalah, sehingga dengan cepat pengambilalihan kekuasaan pemerintah Jepang dapat dilaksanakan." 32

Kutipan ini membuktikan bahwa gerakan di bawah tanah yang berjalan sejak tahun 1939-an berlangsung hingga masa pendudukan tentara Jepang di Sulawesi Tengah. Pada bulan Nopember 1945 kelompok pemuda yang dipimpin oleh A. T. Nurdin dan A. Baro menyerang Bivak atau Pos NICA di KM 4 Donggala dan berhasil menyita satu pucuk karaben dan dua samurai Jepang. ${ }^{33}$

\section{Dinamika setelah Kemerdekaan dan Proses Penetapan Donggala sebagai Kabupaten}

Untuk mempertahakan kemerdekaan, aktivis Laskar Pemuda Indonesia Merdeka (PIM) melakukan sejumlah gerakan sebagai berikut: (1) pada tanggal 11 Nopember 1945, mereka menaikkan bendera merah putih di depan Kantor Doane Donggala setelah merobek bendera Belanda yang berwarna biru sehingga tinggal warna merah putih. ${ }^{34}$ Kegiatan ini merupakan show of force dari pemuda-pemuda Donggala dalam memperlihatkan jati dirinya sebagai pejuang sejati. Kegiatan laskar ini sesuai dengan issue nasional mengenai upaya empat bulan dalam mempertahankan kemerdekaan di wilayah Donggala; (2) pada tahun 1946, Datu Aras dengan kekuatan 40 orang anak muda menyerang

${ }^{32}$ Ibid.,

33 Rusdi Toana dkk. 1990. Sejarah Perjuangan Rakyat Kabupaten Donggala. Palu: Pemerintah Daerah Tingkat II Donggala.

${ }^{34}$ Rusdy Toana dkk, 1990. Sejarah Perjuangan Rakyat Kabupaten Donggala, Hasil Seminar Sejarah Perjuangan Rakyat Kabupaten Donggala. Palu: Pemda Tingkat II Donggala, hal 106. 
pos Nederlands Indische Civiel Administratie (NICA) di Lono atau Ganti serta A. Baro dan Abdul Wahid memimpin 30 orang pemuda untuk menghadang patroli NICA di Salumbone atau Tovale dan juga merusak jembatan agar dapat menghadang NICA di Limboro; (3) pada tahun 1947, A. Baro bersama 25 orang pemuda menghadang patroli NICA di Surumana. Ladising bersama 5 orang pemuda membumihanguskan gedung kopra milik Coprafounds. Pembakaran ini dimaksudkan untuk melumpuhkan kekuatan ekonomi Belanda; dan (4) pada tahun 1948, Umar bersama 25 orang pemuda menyerang patroli NICA di Bambaira.

Pada malam tanggal 11 November 1945, yakni setelah peristiwa perobekan bendera di halaman kantor doane yang dipimpin oleh A. T. Nurdin, Lagama Borahima, Abd. Wahid Maluku, dan Ladising, NICA menelusuri aktivis PIM, sehingga sejumlah pemuda ditangkap. Penangkapan tersebut menimbulkan solidaritas dan kesadaran berbangsa di kalangan pemuda. Karena itu, PIM membentuk sepuluh kesatuan atau sektor-sektor pertahanan untuk membendung keganasan tentara NICA. Sektor-sektor pertahanan tersebut terdiri dari:

1. Sektor kota Donggala: dipimpin oleh Lagama Borahima, Ladising, Sanusi Jengi, dan Lamado.

2. Sektor Kabonga/Loli : dipimpin oleh Umar Kandia, Taha, Muhammad Tang, dan Abu Latake.

3. Sektor Ganti/Surumana: dipimpin oleh Andi Baro L. Datuara Lamakagili, Mislaini La Ujeng, Abd. Wahid Maluku, dan Labatji.

4. Sektor Bambaira: dipimpin oleh Andi Ngaru Pettalolo, Lapalu, Larumpa, dan A. Wahab.

5. Sektor Palu Kota: dipimpin oleh M. Ali Pettalolo, Ismail Masloman, dan M. Amin Alimuda

6. Sektor Palu Barat: dipimpin oleh M. Jabar, Idris Sunusi, dan Arsyad Parampasi

7. Sektor Palu Timur: dipimpin oleh Bestari Borahima, Philips Ranti, dan Umar

8. Sektor Wani: dipimpin oleh A. Baso, dan Abdullah Nento

9. Sektor Tibo: dipimpin oleh Adam 
10. Sektor Banawa Utara : dipimpin oleh A. T Nurdin, Muhammad Habi, A. Hamid, Ismail Kabdina, dan Majid Dansa. ${ }^{35}$

Bulan Desember 1945 para pemuda bertemu di Kaleke dipimpin oleh Hi. Daeng Pawindu, untuk merumuskan strategi menghadapi NICA. Saat itu PIM Donggala diwakili oleh Lagama Borahima, Andi Ngaru Pettalolo, Moh. Tang dan Labatji. Pertemuan berikutnya yang dilaksanakan di Tovale, Watatu, dan Bambaira, berhasil membangun jaringan dengan kelompok pergerakan di Makasar dan mendapat petunjuk dari Ratulangi tentang cara-cara melumpuhkan tentara NICA. Dampak dari pertemuan tersebut, sejumlah aktivis PIM ditangkap kemudian dimasukkan ke dalam tahanan NICA di Besusu.

Pertemuan "rahasia" juga digelar di Biromaru, di rumah Lolonto Mene Lamakarate, untuk merespons instruksi Ratulangi melalui Piolo Isai, agar dapat mempertahankan kemerdekaan. Salah satu keputusan dalam pertemuan tersebut adalah menunjuk Mene Lamakarate sebagai pemimpin yang mengkoordinir pembentukan laskar-laskar yang akan mempertahankan kemerdekaan. Sejumlah laskar segera terbentuk, salah satunya adalah Laskar Pemuda Merah Putih. Di Biromaru, laskar ini dipimpin oleh Mene Lamakarate, di Dolo oleh Dg. M. Gagaramusu, serta di Tavaeli oleh D. M. Lamakarate dan Dj. Jotolembah.

Bertempat di rumah M. Dj. Abdullah di Sidera, Laskar Pemuda Merah Putih melakukan pertemuan untuk membicarakan utusan yang akan ke Makasar melaporkan perkembangan kelaskaran di Sulawesi Tengah. Mene Lamakarate dan D. M. Gagaramusu yang ditunjuk sebagai utusan ke Makasar. Menjelang berakhirnya pertemuan, tentara NICA yang dipimpin Qune Indo mengepung rumah Abdullah dan menangkap Mene Lamakarate, mereka menyita seluruh dokumen yang diketemukan. Penangkapan tersebut ditentang keras oleh Raja Palu dan atas jaminannya, Mene Lamakarate dibebaskan.

Setelah NICA mengetahui ada gerakan di bawah tanah dan mempunyai jaringan dengan Makasar, mereka segera melakukan pengamanan secara ketat dan menangkap orang-orang yang terlibat secara langsung. Pada awal Nopember 1945, A. Monoarfah ditangkap kemudian ditahan di kamp militer

35 Ny. Mas Ulun Andi Bara Lamarauna, 1986. Suatu Hubungan Sosial Masyarakat Kerajaan Banawa Kabupaten Donggala dan Susunan Raja-Raja yang Memerintah. Palu: Tidak Diterbitkan, hal 99. 
NICA. Pada pertengahan Nopember 1945, NICA melakukan penangkapan secara besar-besaran terhadap tokoh-tokoh politik antara lain: Hi. Dg. Pawindu, Hi. Lasingka, Lakacinda, Dg. Pawara, Thalib Latjinala, dan M. Dj. Abdullah. Konsekuensi dari penangkapan tersebut, Lolonto Mene Lamakarate mengkoordinir gerakan yang berkekuatan 1000 orang, berasal dari Tavaili, Kaleke, Pewunu, Dolo, dan Biromaru, dengan bersenjatakan tombak, bambu runcing, guma, dan sumpit.

Lolonto Mene Lamakarate segera bertemu dengan Kapten Barrow untuk menuntut pembebaskan para tahanan politik, jika tidak dibebaskan maka akan terjadi pertumpahan darah. Kapten Barrow menyarankan bahwa sebelum tuntutan tersebut dipenuhi, Lolonto Mene Lamakarate bertemu dengan Dewan Raja-Raja, akhirnya hasil pertemuan tersebut memutuskan untuk membebaskan seluruh tahanan politik. Pada tanggal 11 Pebruari 1946, pemuda yang terdiri dari: Panituru, Sobe, L. Pandan, Dj. Pakamundi, Dg. Matadjo Gagaramusu, Dg. Mangesa Datu Palinge, Andi Nawir Sangi, dan Abd. Hafid Tayeb di bawah pimpinan H.J. Dg. Pawindu mengibarkan bendera merah putih di halaman masjid Al Mujahidin Kaleke. Pertemuan di rumah Hi. J. Dg. Pawindu tanggal 3 Maret 1946, disepakati bahwa laskar-laskar di Sulawesi Tengah harus meningkatkan perlawanan terhadap NICA, dengan cara menggalang persatuan dan kesatuan.

Disadari bahwa perjuangan mempertahankan kemerdekaan tidak cukup jika hanya mengandalkan kekuatan fisik, sehingga sejumlah organisasi sosial dan politik dibentuk. Di Sigi terbentuk Perjuangan Rakyat Indonesia Merdeka (PRIMA) yang diketuai oleh Hi. J. Dg. Pawindu dan sekretaris M. Dj. Abdullah; di Tavaeli terbentuk Gerakan Rakyat Indonesia Merdeka (GERAM) yang pengaruhnya sampai ke Parigi, di ketuai oleh Jondi Maranua dan sekretaris Dg. Maraja Lamakampali; di Wani terbentuk Partai Rakyat Indonesia (PRI) dengan ketua R. Ambija dan sekretaris Junus Sanusi; di Biromaru terbentuk Persatuan Wanita (PERWANI) dengan ketua Ny. Kalsum L. Raja Tiangso dan sekretaris Ny. S. Subaedah Abdullah serta penasehat dr. Suwondo.

Pada tanggal 24 Desember 1946, van Mook membentuk Negara Indonesia Timur (NIT) yang bertujuan untuk memecah Negera Kesatuan Republik Indonesia. Setelah melalui Konferensi Malino dan Konferensi Denpasar tahun 1946, Makasar ditetapkan sebagai ibukota NIT dengan Presiden Tjokorde Gede Rake Sukowati. Dampaknya bagi Sulawesi Tengah, terjadi penyatuan wilayah yang sebelumnya terdiri dari Afdeling Donggala dan Poso menjadi Sulawesi 
Tengah dengan Kepala Daerah Radjawali Muhammad Pusadan yang berkedudukan di Poso.

Pada tanggal 2 Januari 1947, untuk menggalang persatuan di kalangan politisi, maka seluruh partai politik lokal menyatu dalam Gabungan Partai Perjuangan Rakyat Indonesia Sulawesi Tengah (GAPPRIST) dengan susunan pengurus sebagai berikut: Penasehat, dr. Suwondo; Ketua, Hi. Moh. Arsyad (Parindo Wani); Sekretaris, M. Dj. Abdullah (Prima Sigi-Dolo); anggota, Prima Palu, Gerima Tavaeli, Parindo Wani, Prima Sigi-Dolo, Api Palu, dan Perwani Biromaru. Tujuan utama GAPPRIST adalah menghimpun kekuatan untuk meneruskan perjuangan dan membangun jaringan dengan daerah lain terutama Jawa, Sulawesi Selatan, Poso, Tolitoli, dan Gorontalo.

Keputusan politik yang dilahirkan oleh GAPPRIST adalah membuat pernyataan dukungan terhadap keberadaan Pemerintah Republik Indonesia yang berpusat di Yogyakarta dan tidak mengakui NIT. Akibatnya, Asisten Residen Belanda memanggil pimpinan GAPPRIST yang diwakili oleh Djabar Pasau dan M. Dj. Abdullah untuk menjelaskan kedudukan Sulawesi Tengah dalam NIT. Kedua tokoh ini, atas nama GAPPRIST menyatakan menolak keberadaan NIT, ketegasan sikap mereka membesarkan jiwa tokoh pergerakan lainnya sehingga semakin agresif melakukan aksi-aksi penyadaran untuk menjaga keutuhan Republik Indonesia. Bentuk penolakan terhadap NIT dapat dicermati dari isi kawat Ikatan Persatuan Perjuangan Rakyat Indonesia (IPPRI) yang dikirim ke DPR di Makasar sebagai berikut.

Imade geria/dpr empreshotel Makasar kami partai-partai pergerakan sulawesi tengah di Palu koma tavaeli koma donggala dan sigi dolo terdiri dari 29 partai koma memutuskan setuju dan menyokong adanya gerakan pembubaran nit dengan segera dan terbentuknya Negara Kesatuan RI titik habis "IPPRI" (Palu 3 April 1950 ttd rambing abdullah. ${ }^{36}$

Pada bulan Desember 1951 keluar Surat Keputusan penyerahan tugas oleh Radjawali Muhammad Pusadan kepada Abdul Latif Dg. Masikki sebagai Kepala Pemerintahan Negeri (KPN) di Poso dan Ince Nairn Daeng Mamangung sebagai Kepala Pemerintahan Negeri (KPN) di Donggala. Menurut Laporan Politik tahun $1953^{37}$ yang menjadi penggerak terbentuknya Kabupaten Donggala

\footnotetext{
${ }^{36}$ Ibid., hal 114.

${ }^{37}$ Arsip Rahasia Propinsi Sulawesi (Laporan Politik), no registrasi 236.
} 
antara lain: Laparendrengi (Kepala Swapraja Banawa); Abdurachman Mardjukie (Jaksa di Donggala); L.A. Sondakh (Letnan PDM Donggala); A. Supit (Inspeksi); Jondi Maranua (Pegawai Telepon-Central di Tavaeli); Nicolas Djiloy (Asisten Wedana Kulawi); Labaso Borman (Pegawai Kantor Agama Kabupaten Donggala); Andi Raga Pettalolo (Peninjau Bahagian Politik Kantor Daerah Donggala); Frans Josep Mamahit (Kepala Administrasi Kantor Kewedanan Borsumy Donggala); A. Bustan (Klerk Kantor Borsumy Donggala); dan Daeng Maraja Lamakarate (KPN Donggala). Nama-nama tersebut diambil dari kepanitiaan yang disusun untuk Festival Internasional di Jakarta setelah setahun terbentuk Kewedanan Donggala.

Menindaklanjuti Surat Keputusan Gubernur, DPRD-S melaksanakan sidang pada tanggal 16 Nopember 1951 dan secara aklamasi memutuskan dua hal: (1) menyetujui Sulawesi Tengah dipecah menjadi dua daerah yakni Poso dan Donggala, dan (2) membuat pernyataan yang isinya tentang pembekuan DPRD-S dan dewan pemerintahannya serta tugas kekuasaan diserahkan kepada Gubernur Sulawesi dibantu oleh Badan Penasehat yang diangkat oleh Menteri dalam Negeri. Pernyataan tersebut disyahkan oleh Gubernur Sulawesi melalui Surat Keputusan No. 118 tanggal 14 Maret 1952. Pada tanggal 12 Agustus 1952, dikeluarkan Peraturan Pemerintah No. 33 tahun 1952 yang menetapkan bahwa Kabupaten Daerah Tingkat II Donggala ibukota sementara berkedudukan di Palu dengan Kepala Daerah Ince Nairn Dg. Mamangun kemudian Kabupaten Daerah Tingkat II Poso dengan ibukota berpusat di Poso dengan Kepala Daerah Radjawali Muhammad Pusadan.

Konsekuensi dari munculnya kabupaten baru, sejumlah partai politik bermunculan. Menurut Laporan pada tahun 1952, ada dua partai politik baru didirikan di Kabupaten Donggala yakni Masyumi dan Partai Nasional Indonesia (PNI). Pengurus Dewan Pimpinan Cabang Partai Masyumi Kabupaten Donggala dibentuk pada tanggal 22 Desember 1952 dengan susunan pengurus sebagai berikut: Ketua Umum merangkap bendahara, H. N. Parendrengi; Wakil Ketua I, Abdurahman Marzukie; Wakil Ketua II, Jondi Maranua; Sekrtaris, M.Dj. Abdullah; Wakil Sekretaris, Andi Aksa Tombolotutu, sedangkan anggotanya adalah: Said Naser, Said Ali, D. Taleb, dan A. Amu.

Pengurus Dewan Pimpinan PNI Kabupaten Donggala di Palu sebagai berikut: Ketua, Z. Tumbol di Palu; Sekretaris, K. B. Parengkuan; Bendahara, Hasal Albanjar; Ketua Cabang PNI Parigi, H. Pondaag sebagai; Ketua cabang PNI Donggala, L. Lamarauna; Ketua cabang PNI Kaleke, Hadji Daeng 
Pawindu. ${ }^{38}$ PNI cabang Donggala ini terbentuk sejak tanggal 1 Nopember 1952 di Palu.

Delapan tahun kemudian atau pada tahun 1960 pemerintah mengeluarkan Peraturan Pemerintah No. 151/1960 tanggal 13 Desember 1960, yang menetapkan pemekaran Sulawesi menjadi dua Propinsi yakni: Propinsi Sulawesi Selatan Tenggara dengan ibukota Makasar dan Propinsi Sulawesi Utara Tengah dengan ibukota Manado. A. A. Baramuli, SH ditunjuk sebagai Gubernur Propinsi Sulawesi Utara Tengah. Pemekaran ini diikuti dengan penambahan jumlah kabupaten menjadi empat yakni: (1) Kabupaten Daerah Tingkat II Donggala dengan ibukota sementara di Palu; (2) Kabupaten Daerah Tingkat II Poso dengan ibukota di Poso; (3) Kabupaten daerah Tingkat II Buol Tolitoli dengan ibukota di Tolitoli; dan (4) Kabupaten daerah Tingkat II Banggai dengan ibukota di Luwuk.

\section{E. Kesimpulan}

Obsesi Pemerintah Belanda untuk melakukan eksploitasi ekonomi dan hegemoni politik permanen di Donggala pasca pemaksaan "kontrak persahabatan," tidak mudah terwujud karena muncul resistensi dalam bentuk perlawanan fisik seperti; perlawanan Malonda di Donggala, Toma I Dompo Di Sigi, Toma Tarima bersama anaknya di Sojol, dan Toma Itorengke mengobarkan perlawanan di Kulawi.

Pendudukan Jepang mengakhiri penjajahan Belanda setelah pasukan Kaigun tiba di Donggala dengan kapal penjelajah bersama beberapa kapal pemburu torpedo pada bulan april 1942. Pendidikan peninggalan Belanda dihapus dan keberadaan organisasi sosial politik dibrangus kecuali yang mendukung mobilisasi massa untuk kepentingan perang. Pendudukan Jepang meninggalkan penderitaan dan kelangkaan pangan dan pakaian.

Dinamika baru muncul di Donggala setelah kemerdekaan yakni upaya mempertahankan kemerdekaan dari serangan NICA dan perjuangan pembentukan kabupaten Donggala. Untuk menghadapi NICA dilakukan dengan perjuangan fisik dan penggalangan kekuatan sosial politik dengan membentuk; Laskar Pemuda Indonesia Merdeka (PIM), Rakyat Indonesia Merdeka (PRIMA), Gerakan Rakyat Indonesia Merdeka (GERAM), Partai Rakyat Indonesia (PRI), Persatuan Wanita (PERWANI). Sementera itu, upaya

${ }^{38}$ Arsip Rahasia Propinsi Sulawesi (Laporan Politik Sulawesi Tengah), nomor registrasi 236. 
menjadikan Donggala sebagai kabupaten mendapat dua momentum penting yakni: pembentukan Daerah Administratif Donggala berdasarkan Surat Keputusan Gubernur Sulawesi no. 633 tanggal 25 Oktober 1951 dan pembentukan Kabupaten Daerah Tingkat II Donggala berdasakan Peraturan Pemerintah no. 33 tanggal 12 Agustus 1952.

\section{Kepustakaan}

Andi Mas Ulun Parenrengi Lamarauna, 1998. Pelabuhan Donggala dalam Tinjauan Sejarah. Manuskrip

ANRI, "Besluit van Gouverneur Generaal 9 December 1904”, bundel Algemeen Secretarie.

ANRI, “Besluit van Resident Manado 17 Agustus 1931 no. 28/1/3", bundel Algemeen Secretarie.

ANRI, “Agenda Nomor 11952/07", bundel Algemeen Secretarie.

ANRI, Besluit van Gouverneur Generaal 3 Juni 1906 no. 14, bundel Algemeen Secretarie.

ANRI, “Missive van Gouvernement Secretaris tanggal 3 November 1916 no. 461", bundel Algemeen Secretarie.

ANRI, "Nota voor den adviseur voor de bestuurszaken der buitenbezittingen ajun adviseur voor Bestuurszaken der Buitenbezittingen AJ. Knaap", Besluit van Gouverneur Generaal 12 Mei 1917 no. 1, bundel Algemeen Secretarie.

Arsip Rahasia Propinsi Sulawesi (Laporan Politik), no registrasi 236.

Arsip Rahasia Propinsi Sulawesi (Laporan Politik Sulawesi Tengah), nomor registrasi 236. 
Brill, E. J. 1918. La Cartographic Neerlandaise de La Celebes, D'Apres Des Modeles Etrangers 1590-1670, dalam: E.C. Abendanon, Expedition De La Celebes Centra Ie, Voyages Geologiques Et Geographiques A Travers La Celebes Centrale 1909-1910. Leyde: Librairie et Imprimerie Ci-Devant.

H.J. Vingerhoets, 1933. "Coprahcontracten in de Minahassa", dalam Koloniaal Tijdschrift, jilid ke-22

J.A. Campo, 1994. "Steam navigation and state formation", dalam Robert Cribb (ed.) The Late Kolonial State in Indonesia: Political and Economic Foundations of the Netherlands Indies 1880-1942. Leiden: KITLV Press.

J.S. van Braam, 1914. "De Buitenbezittingen en het boschwezen", Tijdschrift voor Binnenlands Bestuur, jilid 47.

Koloniaal Verslag over het jaar 1891, hoofdstuk C.

Koloniaal Verslag over het jaar 1906, hoofdstuk C.

Koloniaal Verslag over het jaar 1907, hoofdstuk C.

Koloniaal Verslag over het jaar 1908, hoofdstuk C.

Koloniaal Verslag over het jaar 1909, hoofdstuk C.

Koloniaal Verslag over het jaar 1915, hoofdstuk C

Koloniaal Verslag over het jaar 1916, hoofdstuk C.

Koloniaal Verslag over het jaar 1917, hoofdstuk C.

Koloniaal Verslag over het jaar 1919, hoofdstuk C

Koloniaal Verslag over het jaar 1920, hoofdstuk C.

Louis Gottschalk, 1986. Terj. Nugroho Notosusanto, Mengerti Sejarah. Jakarta: Penerbit Universitas Indonesia 
Muklis Paeni, 1985. Sejarah Kabupaten Daerah Tk. II Sidenreng-Rappang, Ujung Pandang: Universitas Hasanuddin

Ny. Mas Ulun Andi Bara Lamarauna, 1986. Suatu Hubungan Sosial Masyarakat Kerajaan Banawa Kabupaten Donggala dan Susunan Raja-Raja yang Memerintah. Palu: Tidak Diterbitkan

Rusdi Toana dkk. 1990. Sejarah Perjuangan Rakyat Kabupaten Donggala. Palu: Pemerintah Daerah Tingkat II Donggala.

Staatsblad Nederlansch-Indie No. 366, tahun 1927.

Stibbe, D.G. 1935. Encyclopaedic Van Nederlandsch Indie, S-Gravenhage: Martnus Nijhoff.

T.B. Bottomore, 1971. Sociology: A Guide to Problem and Literature. London: George Alien \& Unwin Ltd

\section{Tentang Penulis.}

Drs. Lukman Nadjamuddin, M. Hum. Dosen Pendidikan Sejarah Fakultas Keguruan dan Ilmu Pendidikan (FKIP) Universitas Tadulako Palu. Menamatkan Program S1 Pendidikan Sejarah FKIP Universitas Tadulako Palu tahun 1991 dan S2 Ilmu Sejarah Universitas Gadjah Mada Yogyakarta tahun 2000. Saat ini menjabat sebagai Pembantu Dekan III Fakultas Keguruan dan Ilmu Pendidikan Universitas Tadulako Palu.

Idrus, S.Pd. SH. Mantan guru sejarah (1995-2006), Dosen Luar Biasa pada Pendidikan Sejarah FKIP-Untad (1996-2003) dan sejak 2006 sebagai widyaiswara pada LPMP Sulawesi Tengah. Menamatkan Program S1 Pendidikan Sejarah Fakultas Keguruan dan Ilmu Pendidikan (FKIP) Universitas Tadulako Palu tahun 1994 dan S1 Ilmu Hukum (Tata Negara) Universitas Muhammadiyah Palu tahun 2007. Saat ini sedang menempuh Program Magister Pendidikan IPS PPS UNY. 